\title{
Oxidative Stress-Mediated Antibacterial Activity of the Total Flavonoid Extracted from the Agrimonia pilosa Ledeb. in Methicillin-Resistant Staphylococcus aureus (MRSA)
}

\author{
Liren He ${ }^{1}$, Han Cheng ${ }^{1}$, Fuxin Chen ${ }^{2}$, Suquan Song ${ }^{1}$, Hang Zhang ${ }^{3}$, Weidong Sun ${ }^{1}$, Xiaowei Bao ${ }^{4}$, \\ Haibin Zhang ${ }^{1}$ and Chenghua $\mathrm{He}^{1, *(\mathbb{D})}$
}

1 College of Veterinary Medicine, Nanjing Agricultural University, Nanjing 210095, China; 2019107090@njau.edu.cn (L.H.); chenghan@stu.njau.edu.cn (H.C.); suquan.song@njau.edu.cn (S.S.); swd100@njau.edu.cn (W.S.); haibinzh@njau.edu.cn (H.Z.)

2 School of Chemistry and Chemical Engineering, Xi'an University of Science and Technology, Xi'an 710054, China; chenfuxin@xust.edu.cn

3 Key Laboratory of Advanced Drug Preparation Technologies, Ministry of Education, Co-Innovation Center of Henan Province for New Drug R \& D and Preclinical Safety, School of Pharmaceutical Sciences, Zhengzhou University, Zhengzhou 450001, China; hangzhang@zzu.edu.cn

4 College of Food Science and Pharmacy, Xinjiang Agricultural University, Urumqi 830052, China; xiaoweibao0723@xjau.edu.cn

* Correspondence: hechenghua@njau.edu.cn; Tel.: +86-025-8439-5227; Fax: +86-025-8439-8669

Citation: He, L.; Cheng, H.; Chen, F.; Song, S.; Zhang, H.; Sun, W.; Bao, X.; Zhang, H.; He, C. Oxidative

Stress-Mediated Antibacterial Activity of the Total Flavonoid Extracted from the Agrimonia pilosa Ledeb. in Methicillin-Resistant Staphylococcus aureus (MRSA). Vet. Sci. 2022, 9, 71. https://doi.org/10.3390/ vetsci9020071

Academic Editors: Valentina Virginia Ebani and Fabrizio Bertelloni

Received: 8 January 2022

Accepted: 3 February 2022

Published: 7 February 2022

Publisher's Note: MDPI stays neutral with regard to jurisdictional claims in published maps and institutional affiliations.

Copyright: (c) 2022 by the authors Licensee MDPI, Basel, Switzerland. This article is an open access article distributed under the terms and conditions of the Creative Commons Attribution (CC BY) license (https:// creativecommons.org/licenses/by/ $4.0 /)$

\begin{abstract}
Background: Methicillin-resistant Staphylococcus aureus (MRSA) is a zoonotic pathogen that causes endocarditis, pneumonia, and skin diseases in humans and livestock. (2) Methods: The antibacterial effect of the total flavonoid against MRSA (ATCC43300) extracted from the Agrimonia pilosa Ledeb. (A. pilosa Ledeb) was evaluated by the microdilution method. The oxidative stresses in MRSA were evaluated by the levels of intracellular hydrogen peroxide $\left(\mathrm{H}_{2} \mathrm{O}_{2}\right)$, reactive oxygen species (ROS), and oxidative stress-related genes. The DNA oxidative damage was tested by the 8-hydroxy-2'-deoxyguanosine (8-OHdG) and DNA gel electrophoresis. The differentially expressed proteins were determined by the method of SDS-PAGE and NanoLC-ESI-MS/MS, while the mRNAs of differential proteins were determined by Real-Time PCR. The changes of ultra-structures in MRSA were observed by Transmission Electron Microscope (TEM). (3) Results: The minimum inhibitory concentration (MIC) of the total flavonoid against MRSA was recorded as $62.5 \mu \mathrm{g} / \mathrm{mL}$. After treatment with the total flavonoid, the levels of intracellular $\mathrm{H}_{2} \mathrm{O}_{2}$ and $\mathrm{ROS}$ were increased and the gene expressions against oxidative stress $(\operatorname{Sod} A, k a t A, \operatorname{Tr} x B)$ were decreased $(p<0.01)$, while the gene expression for oxidative stress (PerR) was increased $(p<0.01)$. The level of intracellular 8-OHdG in MRSA was increased $(p<0.01)$ and the DNA was damaged. The results of TEM also showed that the total flavonoid could destroy the ultra-structures in the bacteria. (4) Conclusions: The total flavonoid extracted from the A. pilosa Ledeb can induce the oxidative stress that disturbed the energy metabolism and protein synthesis in MRSA.
\end{abstract}

Keywords: oxidative stress; total flavonoid; Agrimonia pilosa Ledeb. (A. pilosa Ledeb.); methicillin-resistant Staphylococcus aureus (MRSA)

\section{Introduction}

Staphylococcus aureus (S. aureus) is a zoonotic pathogen that can produce staphylococcal enterotoxin (SE) and lead to serious and sometimes fatal infections in humans [1]. In clinic, it was able to cause endocarditis, pneumonia, osteomyelitis, arthritis, and skin diseases in humans [2], as well as cause mastitis in dairy cows and sheep, exudative epidermitis in piglets, and septicemia in young rabbits [3]. In 1960s, a methicillin-resistant S. aureus (MRSA) strain was first isolated and reported in England [4]. Later on, MRSA was also isolated from the cows, milker's nose [5], poultry farms (breeding hens, laying hens, 
broilers, and turkeys) [6], and pig's nose [7]. MRSA has become a serious threat to food processor, food samples, and customers [8]. Moreover, MRSA infection in hospitals or communities has been reported in many countries [9]. The treatment of MRSA infection has become a thorny problem in clinic. Therefore, searching for an alternative to treat MRSA infection has become an important research focus. This medical plant extract is a promising alternative, which has many advantages including few side effects, low cost, and less susceptibility to bacterial resistance [10].

Agrimonia pilosa Ledeb. (A. pilosa Ledeb) is a rosaceous plant recorded in the Chinese Pharmacopoeia. The decoction of $A$. pilosa Ledeb has been used to treat gastritis, gastric ulcer, diarrhea, and other diseases in humans and livestock [11]. The bioactive compounds in A. pilosa Ledeb include flavonoid, triterpenoids, and isocoumarin, and have been reported to show many pharmacological effects including anti-inflammatory, antidiabetic, antitumor, anti-acetylcholinesterase, antioxidant, antibacterial, and antiparasitic activities [12,13]. It was reported that an ether extract from the $A$. pilosa Ledeb had antibacterial activity against Staphylococcus aureus, bacillus, and Nocardia [14]. However, until now, the effect of the total flavonoid against MRSA extracted from A. pilosa Ledeb and the corresponding bacterial mechanism have never been reported. This study aims to evaluate the antibacterial effects of the total flavonoid against MRSA extracted from A. pilosa Ledeb and to elucidate the oxidative stress-mediated antibacterial mechanism further.

\section{Materials and Methods}

\subsection{Bacterial Strain and Cultivation}

The MRSA strain (ATCC43300) was kept in the clinical microbiology laboratory (Nanjing Agricultural University). The strain MRSA was cultured at $37^{\circ} \mathrm{C}$ in the Mueller-Hinton broth (MHB) and shaken at $180 \mathrm{rpm}$.

\subsection{Preparation of the Total Flavonoid}

The medical plant of $A$. pilosa Ledeb was purchased from Bozhou Traditional Chinese Medicine Market (Bozhou, China) in December 2019 and stored in Nanjing Agricultural University (Voucher no. 20191205). Five hundred grams of dried and powdered A. pilosa Ledeb was sonicated in $3000 \mathrm{~mL}$ ethyl acetate for $30 \mathrm{~min}$ and kept at room temperature for $24 \mathrm{~h}$. The extract was filtrated and lyophilized under reduced pressure. Next, $50 \mathrm{~g}$ of ethyl acetate extract was used to extract the total flavonoid by the method of $60 \%$ alcohol reflux [15]. The total time for the alcohol reflux was $1.5 \mathrm{~h}$. The yield of the total flavonoid from the ethyl acetate extract was $6.3 \%(w / w)$.

\subsection{MIC Determination}

The microdilution method was used to evaluate the MIC in the 96-well plates. In brief, the total flavonoid was double diluted into a 96-well plate from $2 \mathrm{mg} / \mathrm{mL}$, then the plate was dried at $50{ }^{\circ} \mathrm{C}$ for $3 \mathrm{~h}$. After that, $100 \mu \mathrm{L}$ of MRSA ATCC43300 $\left(1 \times 10^{6} \mathrm{CFU} / \mathrm{mL}\right)$ was added into the 96-well plate and the plate was incubated for $12 \mathrm{~h}$ at $37^{\circ} \mathrm{C}$. Next, $50 \mu \mathrm{L}$ of resazurin $(0.5 \mathrm{mg} / \mathrm{mL})$ was added into the plate, and the plate was incubated for a further $1.5 \mathrm{~h}$. The discoloration was used to determine the MIC [16]. Finally, the MIC of the total flavonoid against MRSA was recorded as $62.5 \mu \mathrm{g} / \mathrm{mL}$.

\subsection{HPLC and HRMS Analysis of the Total Flavonoid}

The total flavonoid was detected by high-performance liquid chromatography (HPLC) equipped with a UV detector (Shimadzu Prominence, Japan) and Agilent TC-C18 column $(250 \mathrm{~mm} \times 4.6 \mathrm{~mm}, 5 \mu \mathrm{m})$. The mobile phase A was $5 \%$ acetonitrile $+0.1 \%$ formic acid and mobile phase $B$ was $95 \%$ acetonitrile $+0.1 \%$ formic acid. The gradient elution program was $0.01-5 \min 30 \% \mathrm{~B}, 5-10 \mathrm{~min} 60 \% \mathrm{~B}, 10-40 \mathrm{~min} 65 \% \mathrm{~B}, 40-60 \mathrm{~min} 100 \% \mathrm{~B}$, and $60-65 \mathrm{~min}$ $0 \% \mathrm{~B}$. The detection wavelength, flow rate, column temperature, and sampling volume were $254 \mathrm{~nm}, 0.6 \mathrm{~mL} / \mathrm{min}, 40^{\circ} \mathrm{C}$, and $10 \mu \mathrm{L}$, respectively. 
The total flavonoid was analyzed by the Q Exactive ${ }^{\mathrm{TM}}$ mass spectrometer (Thermo, Waltham, MA, USA), according to the published procedure [17]. In brief, the total flavonoid was dissolved in $95 \%$ acetonitrile $+0.1 \%$ formic acid, and the final concentration was $0.1 \mathrm{mg} / \mathrm{mL}$. Then, $5 \mu \mathrm{L}$ of sample was analyzed by the following conditions: scan mode, FTMS + p ESI full ms; scanning range, 50-1000 m/z; capillary voltage, $3500 \mathrm{~V}$; dry gas, $8 \mathrm{~L} / \mathrm{min}$; temperature, $320{ }^{\circ} \mathrm{C}$. The mass results were analyzed by the software NIST 20 (available online: https:/ / www.sisweb.com/software/ms/nist.htm, accessed on 7 September 2021) including the mass bank library and mainlab database.

\subsection{Determination of Time-Kill Curves}

The total flavonoid was dissolved in $15 \mathrm{~mL}$ MHB with the final concentration of $0.25 \times \mathrm{MIC}, 0.5 \times \mathrm{MIC}, 1 \times \mathrm{MIC}, 2 \times \mathrm{MIC}$, and $4 \times \mathrm{MIC}$, respectively. Ceftiofur sodium $(10 \mu \mathrm{g} / \mathrm{mL}$ ) was used as the positive control (positive group) and the normal MHB was used as the negative control (NC). After adding of the MRSA ATCC43300 strain $\left(1 \times 10^{6} \mathrm{CFU} / \mathrm{mL}\right)$, all tubes were cultured at $37^{\circ} \mathrm{C}$ with shaking at $180 \mathrm{rpm}$. Then, the colony was counted every $2 \mathrm{~h}$ on the MHB agar plate. The time-kill curves were drawn according to the results of the colony counting.

\subsection{The Level of Intracellular $\mathrm{H}_{2} \mathrm{O}_{2}$}

The levels of intracellular $\mathrm{H}_{2} \mathrm{O}_{2}$ in MRSA ATCC43300 were determined by the $\mathrm{H}_{2} \mathrm{O}_{2}$ Assay Kit (Nanjing Jiancheng Bioengineering Institute, Nanjing, China). The MRSA ATCC43300 was cultured at $37^{\circ} \mathrm{C}$ in MHB and shaken at $180 \mathrm{rpm}$. The concentrations of the total flavonoid in tubes were $0.25 \times \mathrm{MIC}, 0.5 \times \mathrm{MIC}, 1 \times \mathrm{MIC}, 2 \times \mathrm{MIC}$, and $4 \times \mathrm{MIC}$, respectively. Ceftiofur sodium $(10 \mu \mathrm{g} / \mathrm{mL})$ was used as the positive control, and the normal MHB was used as the negative control (NC). After coculture for $8 \mathrm{~h}$, the bacteria were collected by centrifugation ( $3000 \mathrm{rpm}, 15 \mathrm{~min}, 4^{\circ} \mathrm{C}$ ) and lysed by ultrasonic waves (200 W, $5 \mathrm{~min}, 4^{\circ} \mathrm{C}$ ). The supernatant was used to measure the level of $\mathrm{H}_{2} \mathrm{O}_{2}$ at $405 \mathrm{~nm}$. At the same time, the total proteins in the supernatant were detected by the protein assay kit (Nanjing Jiancheng Bioengineering Institute, Nanjing, China). The $\mathrm{H}_{2} \mathrm{O}_{2}$ and standard protein concentration $(163 \mathrm{mmol} / \mathrm{L})$ were provided with the kit. The levels of intracellular $\mathrm{H}_{2} \mathrm{O}_{2}$ were calculated by the following formula:

$\mathrm{H}_{2} \mathrm{O}_{2}(\mathrm{mmol} / \mathrm{mg})=\frac{\mathrm{OD}(\text { sample })-\mathrm{OD}(\mathrm{NC})}{\mathrm{OD}(\text { standard })-\mathrm{OD}(\mathrm{NC})} \times \frac{163(\mathrm{mmol} / \mathrm{L})}{\text { total protein concentration of the sample }(\mathrm{mg} / \mathrm{L})}$

\subsection{The Level of Intracellular ROS Analysis}

The levels of intracellular ROS in the $1 \times$ MIC group and NC group were determined by the $2^{\prime}-7^{\prime}$-dichlorofluorescin diacetate (DCFH-DA) with laser confocal microscope. In brief, after co-incubation for $8 \mathrm{~h}$, the bacterial cells were collected by centrifugation (3000 $\mathrm{rpm}, 10 \mathrm{~min}, 4^{\circ} \mathrm{C}$ ) and washed by PBS for three times, then the fluorescent probe DCFH-DA $(10 \mathrm{uM})$ was added and co-incubated for $2 \mathrm{~h}$ at $37^{\circ} \mathrm{C}$ with shaking at $50 \mathrm{rpm}$. After washing with PBS three times, $50 \mu \mathrm{L}$ of bacterial cell $\left(1 \times 10^{6} \mathrm{CFU} / \mathrm{mL}\right)$ was put on the slide, then fixed and observed under the laser confocal microscope. The fluorescence intensity was analyzed by the software of Image J (available online: https:/ /imagej.nih.gov/ij/index.html, accessed on 7 July 2020).

\subsection{Oxidative Stress-Related Genes Analysis}

The Bacterial RNA Extraction Kit (Vazyme Biotech Co., Ltd., Nanjing, China) was used to extract the total RNA in the $1 \times$ MIC group and NC group, respectively. The $16 S$ gene was used as the internal standard for the following analysis. The primers of the oxidative stress-related genes $(\operatorname{sod} A, k a t A, \operatorname{Tr} x B$, and perR) and $16 S$ gene were showed in the Table 1. After reverse transcription, the $C D N A$, relative primers and SYBR qPCR Master Mix (Vazyme Biotech Co., Ltd., Nanjing, China) were mixed and performed by the StepOnePlus ${ }^{\mathrm{TM}}$ Real-Time PCR (Applied Biosystems, CA, USA). The PCR program 
included an initial denaturation for $30 \mathrm{~s}$ at $95^{\circ} \mathrm{C}$, following by 40 cycles of amplification of $95^{\circ} \mathrm{C}$ for $5 \mathrm{~s}$ and $60^{\circ} \mathrm{C}$ for $30 \mathrm{~s}$. The method of $2^{-\Delta \Delta} \mathrm{CT}$ was used to analyze the data of Real-Time PCR.

Table 1. The primers of oxidative stress related genes $(\operatorname{sod} A, k a t A, \operatorname{Tr} x B$, and $\operatorname{per} R)$.

\begin{tabular}{lll}
\hline \multicolumn{1}{c}{ Name } & \multicolumn{1}{c}{ Forward Primer $\left(\mathbf{5}^{\prime} \rightarrow \mathbf{3}^{\prime}\right)$} & \multicolumn{1}{c}{ Reverse Primer $\left(\mathbf{5}^{\prime} \rightarrow \mathbf{3}^{\prime} \mathbf{)}\right.$} \\
\hline $16 s$ & CCAGCAGCCGCGGTAAT & CGCGCTTTACGCCCAATA \\
sodA & AAGCGTGTTCCCATACGTCTAAACC & TTGGTTCAGGTTGGGCTTGGTTAG \\
kat $A$ & GCTGCTGAAATTATAGCTACAGAT & TACTTGAATATACATTGTCCATTT \\
$\operatorname{Tr} x B$ & AAGACGGCAAAGTGGGTTCTGTG & TGGCGCTGTTAATGGCTTCATACC \\
$p e r R$ & TCCATTCGATGATGTGTTACGTCA & TGTGAACAATGTGGTAAGATCGTTG \\
\hline
\end{tabular}

\subsection{8-Hydroxy-2'-Deoxyguanosine (8-OHdG) and DNA Gel Electrophoresis}

The levels of 8 -OHdG in the $0.25 \times \mathrm{MIC}, 0.5 \times \mathrm{MIC}, 1 \times \mathrm{MIC}, 2 \times \mathrm{MIC}, 4 \times \mathrm{MIC}$, positive, and NC group were determined by the 8-OHdG ELISA kit (Jiangsu Meibiao Biotechnology Co., Ltd., Suzhou, China) [18]. The MRSA ATCC43300 was cultured at $37^{\circ} \mathrm{C}$ and shaken at $180 \mathrm{rpm}$ in $\mathrm{MHB}$. After co-incubation for $8 \mathrm{~h}$, the bacteria were collected by centrifugation ( $3000 \mathrm{rpm}, 15 \mathrm{~min}, 4^{\circ} \mathrm{C}$ ) and lysed by ultrasonic waves $\left(200 \mathrm{~W}, 5 \mathrm{~min}, 4^{\circ} \mathrm{C}\right)$. The absorbance of the supernatant at $450 \mathrm{~nm}$ was used to measure the level of 8-OHdG. Different concentration of 8-OHdG was used to establish the standard curve, then the concentration of $8-\mathrm{OHdG}$ in the sample was calculated by the standard curve.

The levels of DNA damage in the $0.25 \times \mathrm{MIC}, 0.5 \times \mathrm{MIC}, 1 \times \mathrm{MIC}, 2 \times \mathrm{MIC}$, $4 \times$ MIC, positive, and NC group were evaluated by DNA gel electrophoresis [19]. After co-incubation for $8 \mathrm{~h}$, the bacteria were collected by centrifugation and lysed by the lysozyme, then the total DNA was extracted by the bacterial genomic DNA Extraction Kit (Vazyme Biotech Co., Ltd., Nanjing, China). The extracted DNA was detected by the 1\% agarose gel electrophoresis and taken a photo for analysis.

\subsection{SDS-PAGE and NanoLC-ESI-MS/MS Analysis}

The strain MRSA ATCC43300 was cultured at $37^{\circ} \mathrm{C}$ and shaken at $180 \mathrm{rpm}$ in $\mathrm{MHB}$ which contained $1 \times$ MIC of the total flavonoid. The normal MHB was used as the negative control (NC). After co-incubation for $8 \mathrm{~h}$, the bacteria were collected by centrifugation (3000 $\mathrm{rpm}, 15 \mathrm{~min}, 4^{\circ} \mathrm{C}$ ) and washed with PBS three times. Then, the total proteins were extracted for protein gel electrophoresis. After staining with Coomassie dye, the gel was taken photo and the density of the differential protein bands was analyzed by the software of Image J (available online: https: / / imagej.nih.gov/ij/index.html, accessed on 7 July 2020).

The differential protein bands were cut and analyzed by the method of NanoLC-ESIMS/MS [20]. In brief, the cut protein bands were digested with modified trypsin (Promega) and the digested peptides were extracted out with acetonitrile. Then the extracted peptides were dried and redissolved in a sample solution ( $2 \%$ acetonitrile $97.5 \%$ water, $0.5 \%$ formic acid). The peptides were analyzed by NanoLC-ESI-MS/MS. The data were analyzed by the software PLGS (v 2.3) and searched in the KEGG database (available online: https: / / www.kegg.jp/, accessed on 6 August 2021).

\subsection{The mRNA Expression Analysis of Differential Proteins}

The primers for the differential protein genes ( $c r r, r p l D, f b a, f d a, p d h B$, and 16S) were shown in Table 2. The RNA extract and the method of Real-Time PCR were the same as that in the section of oxidative stress-related genes analysis. 
Table 2. The primers for the gene of $c r r, r p l D, f b a, f d a$, and $p d h B$.

\begin{tabular}{lll}
\hline \multicolumn{1}{c}{ Name } & \multicolumn{1}{c}{ Forward Primer $\left(\mathbf{5}^{\prime} \rightarrow \mathbf{3}^{\prime}\right)$} & \multicolumn{1}{c}{ Reverse Primer $\left(\mathbf{5}^{\prime} \rightarrow \mathbf{3}^{\prime}\right)$} \\
\hline$c r r$ & TCCTTCGCCGTCTAATTGAACTGTG & GCAGGACGTGTTGACAATGTCTTTC \\
$r p l D$ & ACTTCTTGGAGTTGGTCCGAATACG & GGAACAGGTCGTGCTCGTCAAG \\
$f b a$ & ACTGAACCTAATGCTGGCGCTAATG & ACTGTTGGCGGACAAGAAGATGATG \\
$f d a$ & TGTTCCAACTTGTTCACGATATGCG & GCAGTGTATTTGCCTTCTACTTCGC \\
$p d h B$ & TTGATGCGATTGCTGGACAAATTGC & TGTGTGTACGCCACCACCAAATG \\
$16 s$ & CCAGCAGCCGCGGTAAT & CGCGCTTTACGCCCAATA \\
\hline
\end{tabular}

\subsection{Transmission Electron Microscope (TEM) Observation}

The bacteria in the $1 \times$ MIC and NC group were observed by the TEM (HT7700, HITACHI), respectively. The strain MRSA ATCC43300 was cultured at $37^{\circ} \mathrm{C}$ and shaken at $180 \mathrm{rpm}$ in MHB which contained $1 \times$ MIC of the total flavonoid. The normal MHB was used as the negative control (NC). After cocultivation for $8 \mathrm{~h}$, the bacteria were collected by centrifugation ( $3000 \mathrm{rpm}, 15 \mathrm{~min}, 4{ }^{\circ} \mathrm{C}$ ) and washed with PBS three times. Then, the bacterial cells were fixed by $2.5 \%$ glutaraldehyde at $4{ }^{\circ} \mathrm{C}$ overnight and observed by TEM [21].

\subsection{Statistical Analysis}

All experiments were repeated three times and analyzed by software SPSS 13.0 with the method of One-Way ANOVA. \#\# means $p$-value $<0.01$ and \# means $p$-value $<0.05$.

\section{Results}

\subsection{HPLC and HRMS Analysis of the Total Flavonoid Extracted from the A. pilosa Ledeb.}

The chromatogram of the total flavonoid extracted from the A. pilosa Ledeb is shown in Figure 1. Compared with the mass spectrum data and literatures, 10 flavonoid compounds were found in the total flavonoid extracted from the $A$. pilosa Ledeb, including apigenin [22], kaempferol [23], kaempferol-3-O-glucoside [24], luteolin [25], quercetin [26], taxifolin [27], tiliroside [28], isoquercetin [29], rutin [27], and vitexin [30] (Table S1). The total ion chromatogram of the total flavonoid is available in the Supplementary Materials (Figure S1).

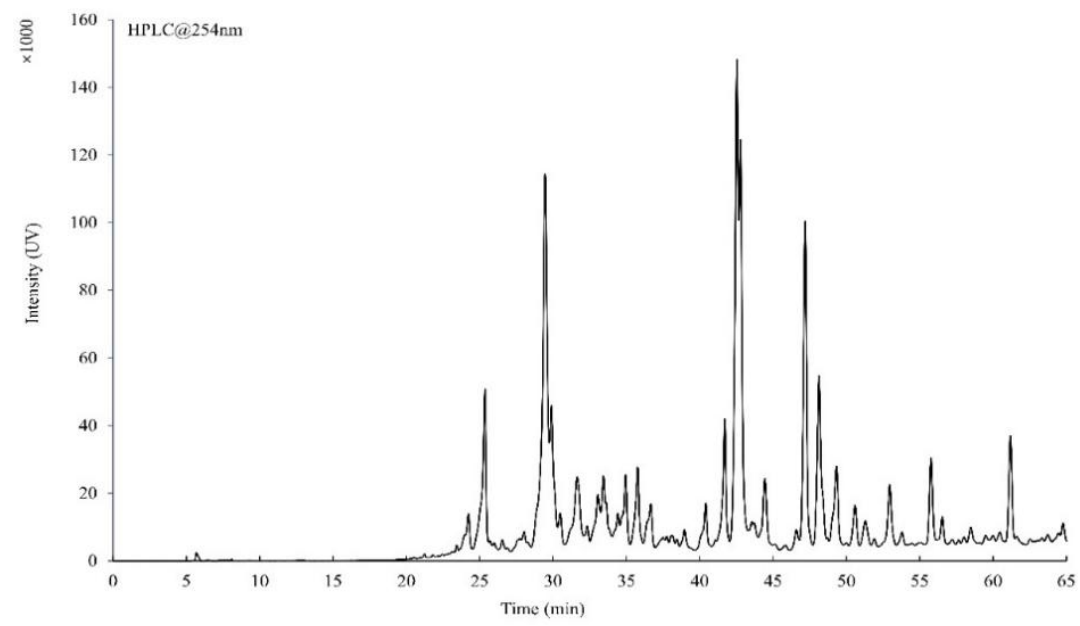

Figure 1. The chromatogram of the total flavonoid extracted from the A. pilosa Ledeb at $254 \mathrm{~nm}$.

\subsection{The Time-Kill Curves}

The time-kill curves of the total flavonoid against MRSA ATCC43300 showed that, at the low concentration of the total flavonoid $(0.25 \times \mathrm{MIC}$ and $0.5 \times \mathrm{MIC})$, the bacteriostasis on MRSA ATCC43300 was very weak. However, at the high concentration of the total flavonoid $(1 \times \mathrm{MIC}, 2 \times \mathrm{MIC}$, and $4 \times \mathrm{MIC})$, the bacteriostasis was increased. After $10 \mathrm{~h}$, 
the number of MRSA ATCC43300 decreased to the undetectable level (Figure 2). These results indicate that the total flavonoid extracted from the A. pilosa Ledeb can inhibit the growth of MRSA ATCC43300.

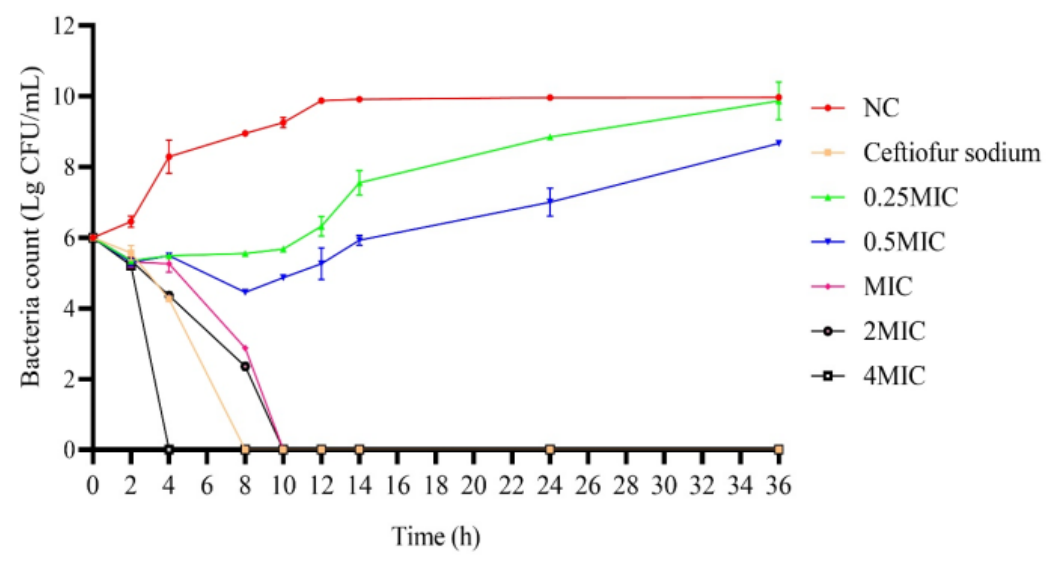

Figure 2. The time-kill curves for the total flavonoid against MRSA ATCC43300 at different concentrations $(4 \times \mathrm{MIC}, 2 \times \mathrm{MIC}, 1 \times \mathrm{MIC}, 0.5 \times \mathrm{MIC}$, and $0.25 \times \mathrm{MIC})$. Ceftiofur sodium was used as the positive control. The normal MHB was set as the negative control (NC).

\subsection{The Level of Intracellular $\mathrm{H}_{2} \mathrm{O}_{2}$}

After treatment with the total flavonoid extracted from the A. pilosa Ledeb, the levels of intracellular $\mathrm{H}_{2} \mathrm{O}_{2}$ were significantly increased $(p<0.01)$ compared with the NC group (Figure 3). Moreover, with the increase of the concentration, the level of intracellular $\mathrm{H}_{2} \mathrm{O}_{2}$ in MRSA ATCC 43300 also increased. These results suggest that the total flavonoid extracted from the A. pilosa Ledeb can significantly increase the level of intracellular $\mathrm{H}_{2} \mathrm{O}_{2}$ in MRSA ATCC43300.

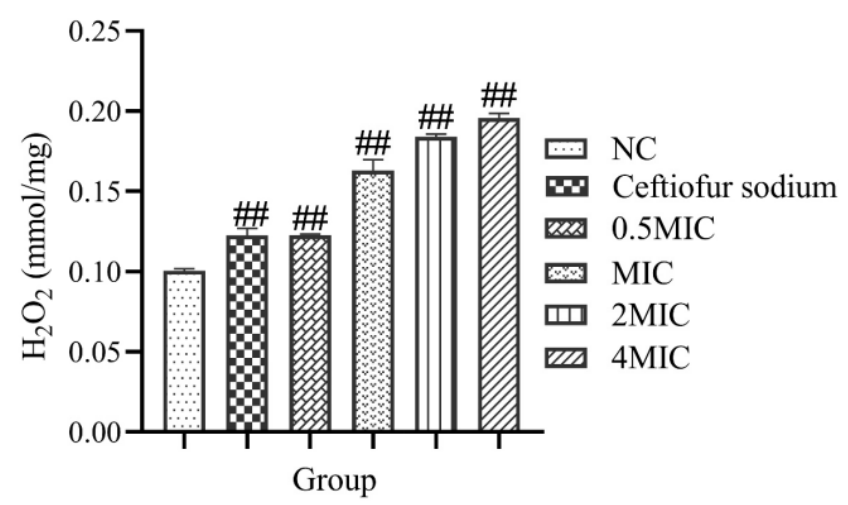

Figure 3. The levels of intracellular $\mathrm{H}_{2} \mathrm{O}_{2}$ in MRSA ATCC43300 after the treatment with different concentrations of the total flavonoid extracted from A. pilosa Ledeb. The Ceftiofur sodium was used as positive control. The normal MHB was set as the negative control (NC). \#\# means $p$-value $<0.01$.

\subsection{The Level of Intracellular ROS}

Compared with the NC group, the fluorescence intensity under the laser confocal microscope was increased significantly after treatment with the $1 \times$ MIC of total flavonoid (Figures 4 and S2). These results show that the total flavonoid extracted from the A. pilosa Ledeb can significantly increase the production of ROS in MRSA ATCC43300. 


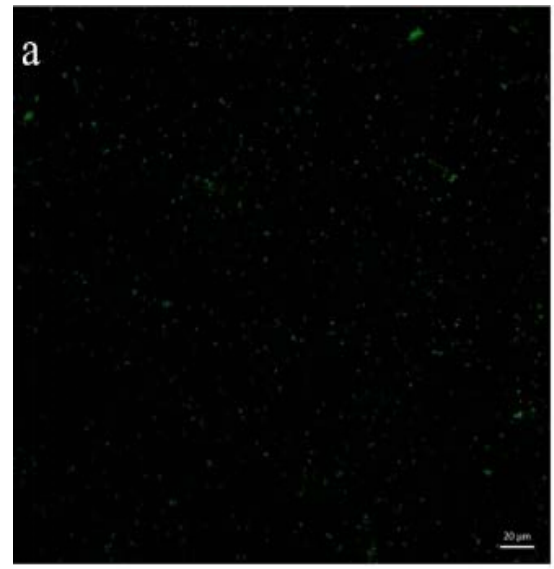

$\mathrm{NC}$

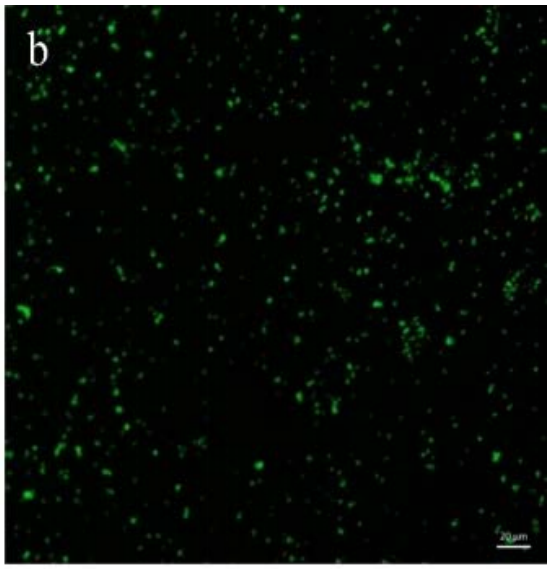

MIC

Figure 4. The levels of intracellular ROS in MRSA ATCC43300 after treatment of the total flavonoid extracted from the A. pilosa Ledeb. The normal MHB was set as the negative control (NC). (a) was the NC group, (b) was the $1 \times$ MIC group.

\subsection{Oxidative Stress-Related Genes}

Compared with the NC group, the mRNA expressions of $\operatorname{Sod} A, k a t A$, and $\operatorname{Tr} x B$ were decreased significantly in the $1 \times$ MIC group, however, the mRNA expression of PerR was increased significantly $(p<0.01)$ (Figure 5$)$. The results show that the total flavonoid extracted from the $A$. pilosa Ledeb can enhance the level of oxidative stress in MRSA ATCC43300 by regulating the expressions of oxidative stress-related genes.

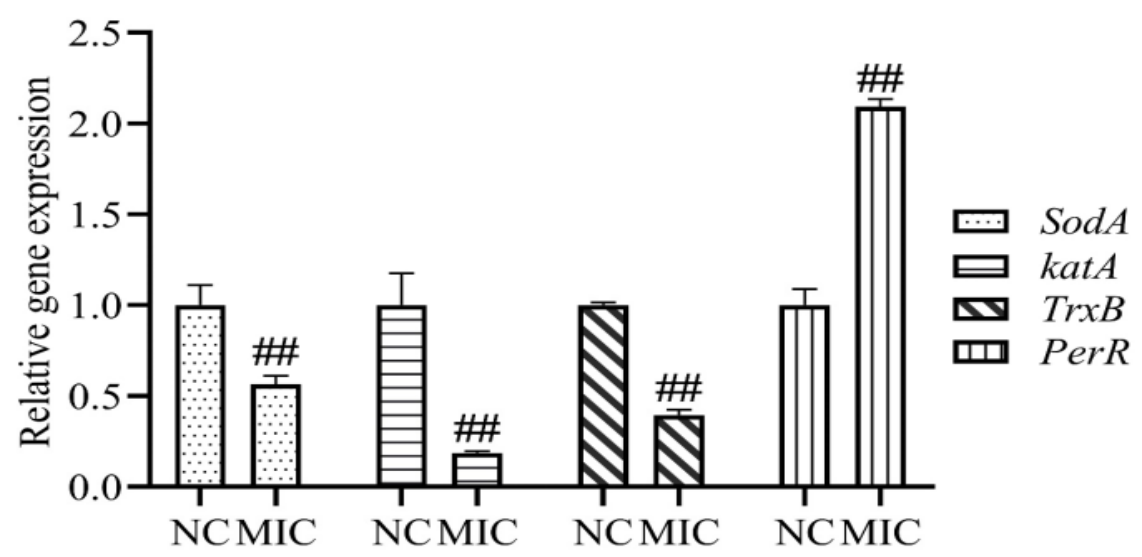

Figure 5. The relative gene expressions of $\operatorname{Sod} A, k a t A, \operatorname{Tr} x B$, and $\operatorname{PerR}$ after treatment of the total flavonoid extracted from the $A$. pilosa Ledeb. The normal MHB was set as the negative control (NC). \#\# means $p$-value $<0.01$.

\subsection{8-OHdG and DNA Gel Electrophoresis}

The level of 8-OHdG was calculated by the following standard curve:

$\mathrm{Y}=0.0276 \mathrm{X}+0.0245\left(\mathrm{R}^{2}=0.9862\right)$

$\mathrm{Y}$ is the concentration of $8-\mathrm{OHdG}(\mathrm{ng} / \mathrm{mg}) ; \mathrm{X}$ is the OD value of sample.

The levels of 8-OHdG in MRSA ATCC43300 were increased significantly after treatment with the total flavonoid $(p<0.01)$ (Figure 6$)$. The results of DNA gel electrophoresis showed that the DNA trailing was increased significantly after treatment with the total flavonoid (Figure 7). The results show that the total flavonoid extracted from the A. pilosa Ledeb can induce DNA oxidative damage in the MRSA ATCC43300. 


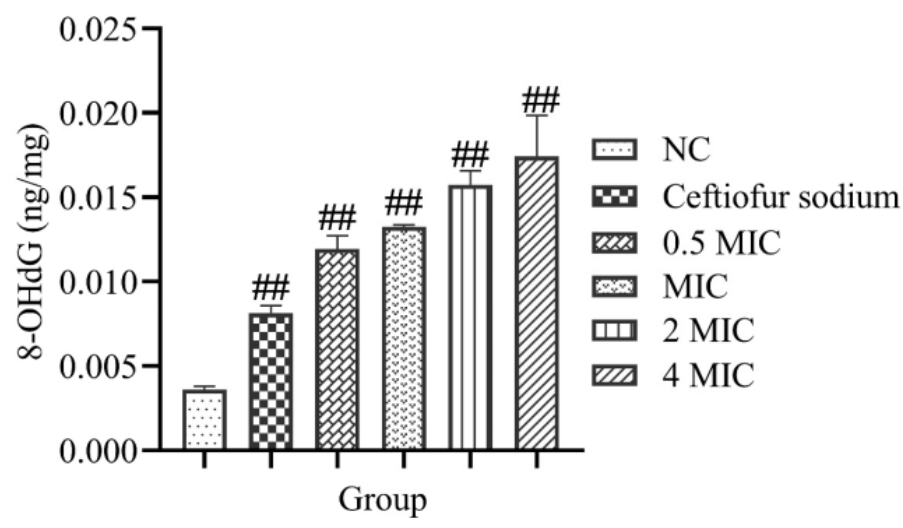

Figure 6. The levels of 8-OHdG in MRSA ATCC43300 after treatment of the total flavonoid extracted from the A. pilosa Ledeb. The normal MHB was set as the negative control (NC). \#\# means $p$-value $<0.01$.

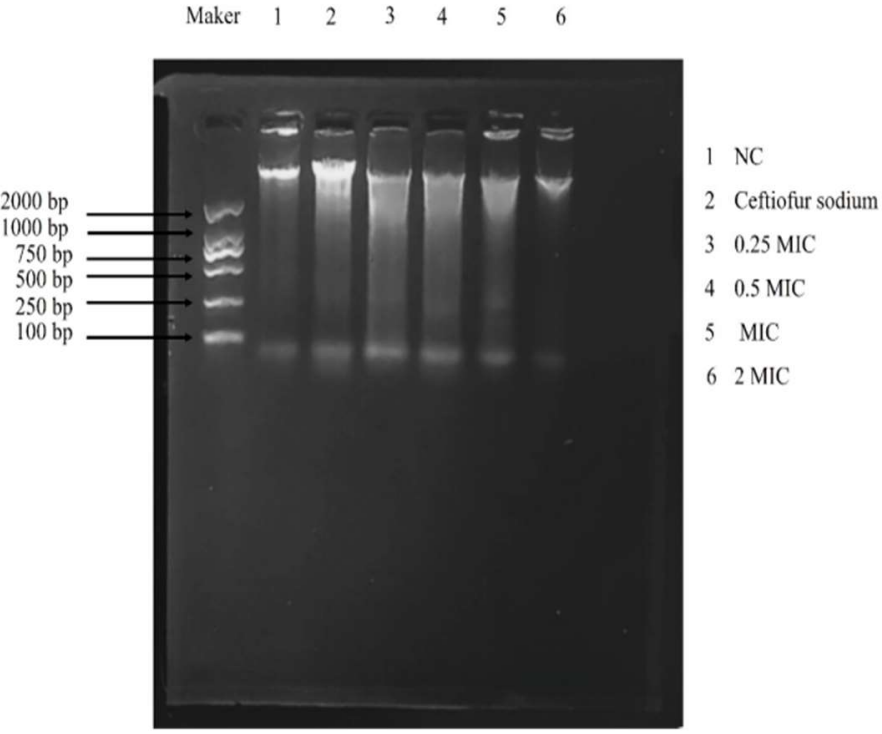

Figure 7. The DNA gel electrophoresis after treatment of the total flavonoid extracted from the $A$. pilosa Ledeb. The normal MHB was set as the negative control (NC).

\subsection{SDS-PAGE and NanoLC-ESI-MS/MS Analysis}

Compared with the NC group, the a-band (15-25 kDa), b-band (15-25 kDa), c-band (25-35 kDa), d-band (about $35 \mathrm{kDa})$, and e-band (35-40 kDa) were significantly downregulated proteins (Figure 8). The results of NanoLC-ESI-MS/MS showed that the a-band, b-band, c-band, d-band, and e-band were PTS system glucose-specific EIIA component, $50 \mathrm{~S}$ ribosomal protein L4, Fructose-bisphosphate aldolase, Fructose-bisphosphate aldolase class 1, and Pyruvate dehydrogenase E1 component subunit beta, respectively (Figure S3). The densitometry analysis of differential proteins (a-band, b-band, c-band, d-band, and e-band) is available in the Supplementary Materials (Figure S4). These results suggest that the total flavonoid extracted from the A. pilosa Ledeb can significantly inhibit the protein synthesis in MRSA ATCC43300. 


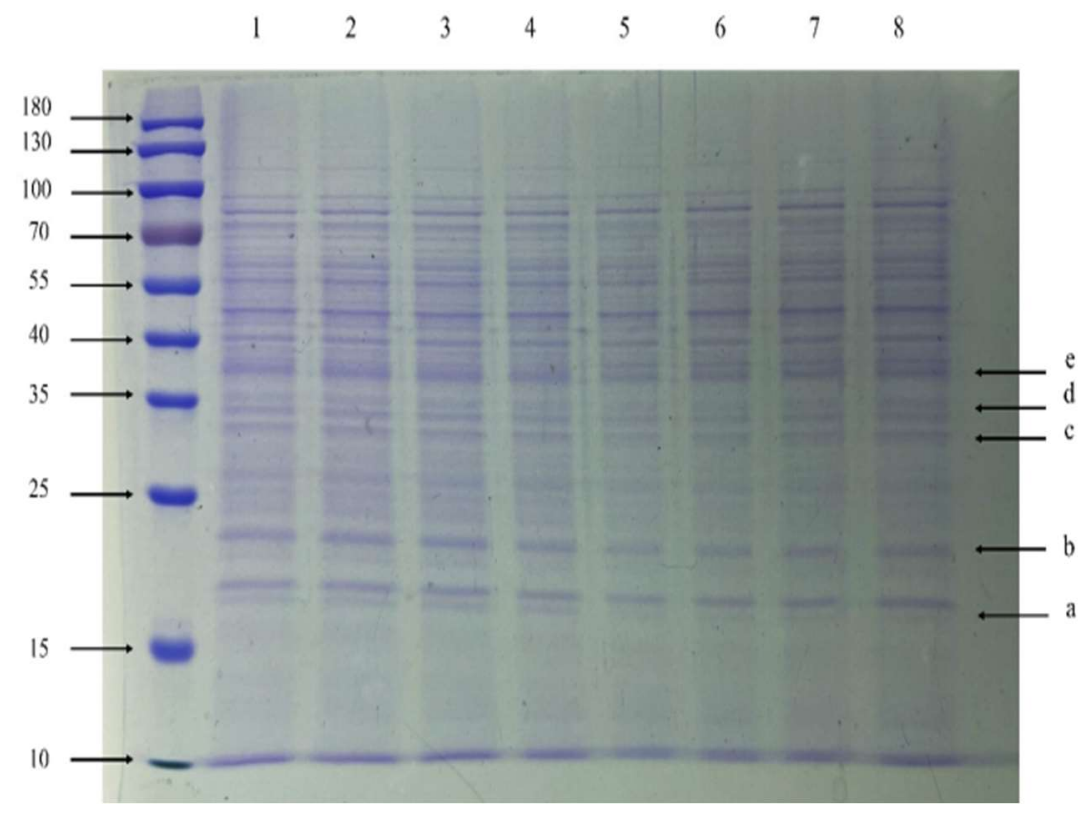

Figure 8. The SDS-PAGE of the total proteins from MRSA ATCC43300 after treatment of the total flavonoid extracted from the A. pilosa Ledeb. Lanes 1-4 were the proteins from the NC group and Lanes $5-8$ were the proteins from the $1 \times$ MIC group. Labels (a-e) indicated the differentially expressed protein bands selected for NanoLC-ESI-MS/MS analysis.

\section{8. mRNA Expression of Differential Proteins}

Compared with the NC group, the mRNA expressions of $c r r, r p l D, p d h B$, and fda were decreased significantly after the treatment with the $1 \times$ MIC total flavonoid $(p<0.01)$, moreover, the mRNA expressions of $f b a$ also decreased $(p<0.05)$ (Figure 9). The results of mRNA expression of differential proteins are in accord with the result of SDS-PAGE.

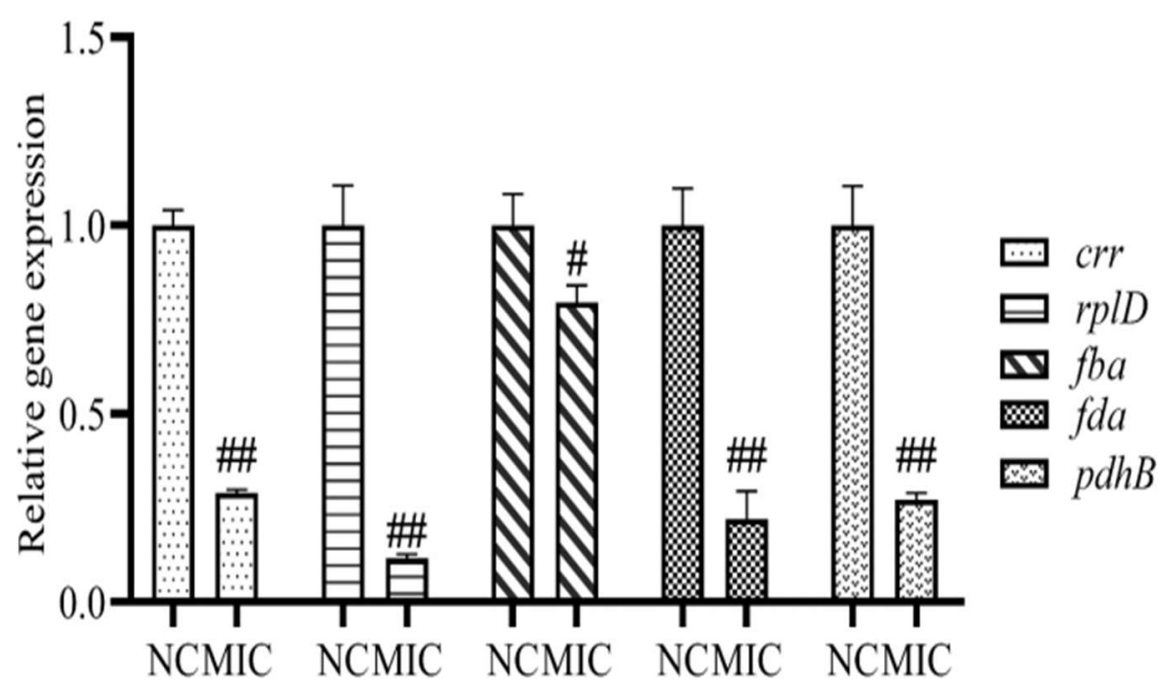

Figure 9. The mRNA expressions of $c r r, r p l D, p d h B, f b a$, and $f d a$ after treatment of the total flavonoid extracted from the $A$. pilosa Ledeb. The normal MHB was set as the negative control (NC). \#\# means $p$-value $<0.01$ and \# means $p$-value $<0.05$.

\subsection{TEM}

The ultra-structures of bacterial cells in the NC group were clear (Figure 10a1,a2). However, after treatment with the $1 \times$ MIC of total flavonoid, the nucleoid in bacteria had almost disappeared, and the cell wall was deformed. The "empty" areas and some areas 
filled with grains were found in the $1 \times$ MIC group (Figure 10b1,b2). The results indicate that the total flavonoid can destroy the ultra-structures in MRSA ATCC43300.
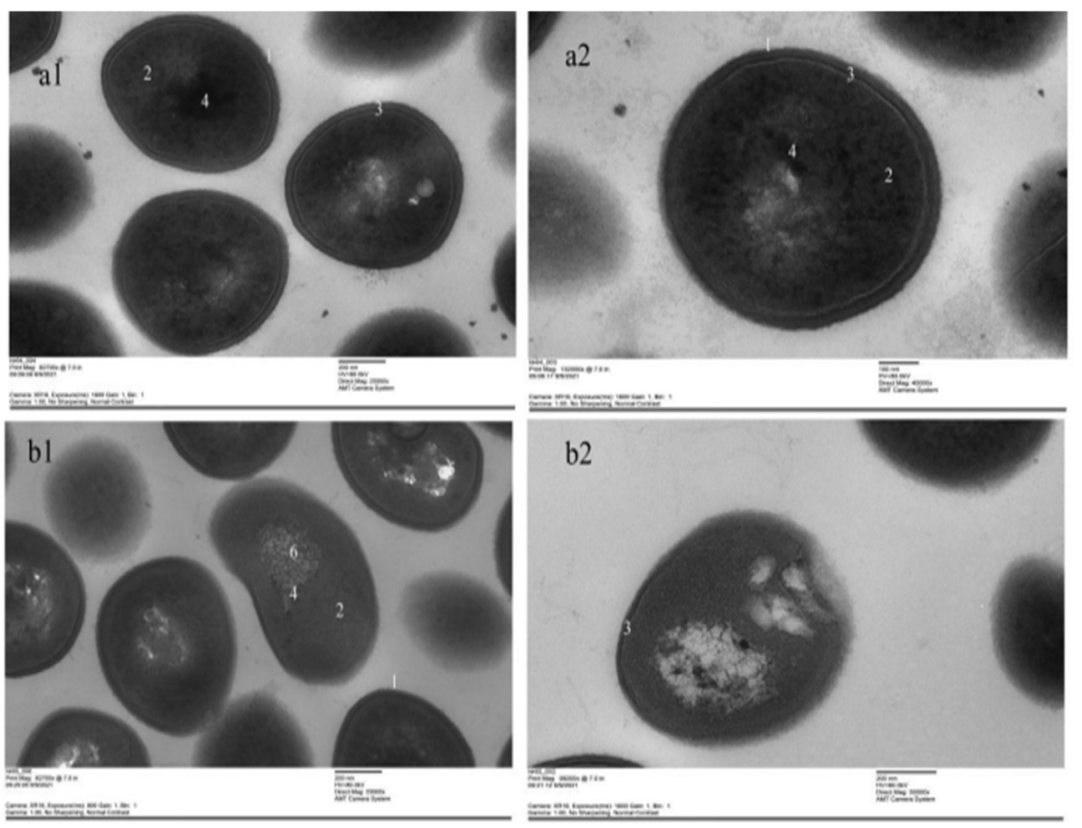

Figure 10. The ultra-structural changes of MRSA ATCC43300 were observed by TEM. (a1,a2) were the NC group. (b1,b2) were the $1 \times$ MIC group. 1-cell wall; 2-cytoplasm; 3-intermediate layer; 4-nucleoid; 5- "empty" areas; 6-areas filled with grains. ((a1,b1), 25,000×; (a2), 40,000×; (b2) $30,000 \times$ ).

\section{Discussion}

MRSA is an important zoonotic pathogen in the field of veterinary and public health which has infected globally in hospitals and communities [31]. It becomes more and more difficult to use antibiotics to treat the MRSA infection in clinic, therefore, an alternative to treat MRSA is needed [32]. The extract of Canarium odontophyllum Miq. [33] and the methanol extract of grape seed [34] were reported to have the activity of anti- MRSA. The extract of $A$. pilosa Ledeb was also reported to have the anti-bacterial activity against MRSA (MIC: $0.1-0.78 \mathrm{mg} / \mathrm{mL}$ ) [35]; however, the antibacterial mechanism of the extract of A. pilosa Ledeb has never been reported.

Oxidative stress has become a promising antibacterial strategy that focused on the production of reactive oxygen species (ROS) in the bacteria in order to disturb the balance between oxidation and antioxidation [36]. In this work, after treatment with the total flavonoid, the levels of ROS and $\mathrm{H}_{2} \mathrm{O}_{2}$ in MRSA were increased significantly. SodA, katA, $\operatorname{Tr} x B$, and PerR are the key regulatory genes for oxidative stress in MRSA. The SodA, katA, and $\operatorname{Tr} x B$ are the coding gene of Mn-superoxide dismutase, catalase, and thioredoxin reductase, respectively, which are responsible for the ROS scavenging in the MRSA. However, the $\operatorname{Per} R$ is the coding gene of the peroxide resistance regulator which is sensitive to $\mathrm{H}_{2} \mathrm{O}_{2}$ [37]. Our results indicated that the oxidative stress was inspired after treatment with the total flavonoid. 8-OHdG is a product of oxidized nucleoside of DNA induced by oxidative stress and is a reliable marker of oxidative stress [38]. In this present work, the generation of 8 -OHdG was increased significantly, suggesting that the DNA in MRSA ATCC43300 was damaged by the ROS and $\mathrm{H}_{2} \mathrm{O}_{2}$ induced by the total flavonoid.

Glucose is the most important carbon source in bacteria. The metabolism of glucose is regulated by phosphoenolpyruvate: glucose phosphotransferase system (PTS) [39]. PTS system glucose-specific EIIA component is a transport system of carbohydrates in bacteria, which is a carbohydrate-specific protein composed of three domains (EIIA, EIIB, EIIC) [40]. Pyruvate dehydrogenase complex (PDC) is one of the key enzymes involved in 
glucose metabolism under the aerobic condition. It catalyzes the conversion of pyruvate to acetyl coenzyme A, which is an important part of the metabolic energy pathway of organisms [41]. Pyruvate dehydrogenase E1 $\beta$ is one of the important catalytic enzymes [42], encoded by the $p d h B$ gene, which is responsible for the oxidative decarboxylation and energy metabolism of pyruvate. The fructose-bisphosphate aldolase, also called aldolase, is a glycolytic enzyme that catalyzes the conversion of fructose 1-6-diphosphate to glyceraldehyde 3-phosphate (G3P) and dihydroxy-acetone phosphate (DHAP) via the glycolysis metabolic pathway [43]. It also catalyzes the reversible aldol condensation of DHAP with G3P in gluconeogenesis and Calvin cycle. Fructose-bisphosphate aldolase class 1 utilizes an active-site lysine residue to form a Schiff base with the substrate as part of the reaction mechanism. This protein is involved in step 4 of the sub-pathway that synthesizes D-glyceraldehyde 3-phosphate and glycerophosphate from D-glucose [44]. $50 \mathrm{~S}$ ribosomal protein L4 is one of the main rRNA binding proteins [45]. The protein initially binds to the $5^{\prime}$ end of $23 \mathrm{~S}$ rRNA. It has multiple contacts with assembled $50 \mathrm{~S}$ subunits and different domains of 23S rRNA in the ribosome [46]. The decreased mRNA expression of 50S ribosomal protein L4 indicates that the ribosome function is inhibited and the efficiency of protein synthesis is also reduced. Our results showed that after treatment with the total flavonoid extracted from the A. pilosa Ledeb, the expressions of proteins and relevant mRNAs were decreased. It was speculated that the total flavonoid could inhibit the glycolysis pathway and affected energy metabolism.

\section{Conclusions}

The total flavonoid extracted from the A. pilosa Ledeb could inhibit the growth of MRSA ATCC 43300, and the MIC was $62.5 \mu \mathrm{g} / \mathrm{mL}$. Its antibacterial mechanism was oxidative stress induced by the total flavonoid extracted from the A. pilosa Ledeb that disturbed the energy metabolism and protein synthesis in MRSA.

Supplementary Materials: The following supporting information can be downloaded at: https: / / www.mdpi.com/article/10.3390/vetsci9020071/s1. Table S1. The list of flavonoid compounds extracted from the A. pilosa Ledeb; Figure S1. The total ion chromatogram of the total flavonoid extracted from the A. pilosa Ledeb; Figure S2. The fluorescence intensity of intracellular ROS in MRSA ATCC43300 analyzed by the Image J software; Figure S3. The total ion chromatogram of the a-band, b-band, c-band, d-band, and e-band cut from the SDS-PAGE; Figure S4. The densitometry analysis of a-band, b-band, c-band, d-band, and e-band by the Image J software.

Author Contributions: Conceptualization, C.H. and W.S.; methodology, F.C.; software, H.C.; validation, S.S. and H.Z. (Haibin Zhang); formal analysis, F.C.; investigation, L.H.; resources, H.Z. (Hang Zhang); data curation, L.H.; writing—original draft preparation, L.H.; writing—review and editing, L.H., H.C., and H.Z. (Hang Zhang); visualization, X.B.; supervision, H.Z. (Haibin Zhang); project administration, C.H.; funding acquisition, W.S. All authors have read and agreed to the published version of the manuscript.

Funding: This research was funded by the National Key R\&D Program of China, grant number. 2016YFD0500800-10, the National Natural Science Foundation of China, grant number 30901091 and the Natural Science Foundation of Jiangsu Province, grant number BK2012220.

Institutional Review Board Statement: Ethical review and approval were waived for this study, due to only bacteria was used to study in vitro.

Informed Consent Statement: Not applicable.

Data Availability Statement: Data are available on request from the corresponding author.

Conflicts of Interest: The authors declare no conflict of interest.

\section{References}

1. Parisi, A.; Caruso, M.; Normanno, G.; Latorre, L.; Miccolupo, A.; Fraccalvieri, R.; Intini, F.; Manginelli, T.; Santagada, G. MRSA in swine, farmers and abattoir workers in Southern Italy. Food Microbiol. 2019, 82, 287-293. [CrossRef] 
2. Dayan, G.H.; Mohamed, N.; Scully, I.L.; Cooper, D.; Begier, E.; Eiden, J.; Jansen, K.U.; Gurtman, A.; Anderson, A.S. Staphylococcus aureus: The current state of disease, pathophysiology and strategies for prevention. Expert Rev. Vaccines 2016, 15, 1373-1392. [CrossRef]

3. Peton, V.; Le Loir, Y. Staphylococcus aureus in veterinary medicine. Infect. Genet. Evol. 2014, 21, 602-615. [CrossRef]

4. $\quad$ Barber, M. Methicillin-resistant Staphylococci. J. Clin. Pathol. 1961, 14, 385-393. [CrossRef]

5. Magro, G.; Rebolini, M.; Beretta, D.; Piccinini, R. Methicillin-resistant Staphylococcus aureus CC22-MRSA-IV as an agent of dairy cow intramammary infections. Vet. Microbiol. 2018, 227, 29-33. [CrossRef]

6. Benrabia, I.; Hamdi, T.M.; Shehata, A.A.; Neubauer, H.; Wareth, G. Methicillin-Resistant Staphylococcus aureus (MRSA) in Poultry Species in Algeria: Long-Term Study on Prevalence and Antimicrobial Resistance. Vet. Sci. 2020, 7, 54. [CrossRef]

7. Baba, K.; Ishihara, K.; Ozawa, M.; Tamura, Y.; Asai, T. Isolation of meticillin-resistant Staphylococcus aureus (MRSA) from swine in Japan. Int. J. Antimicrob. Agents 2010, 36, 352-354. [CrossRef]

8. Jones, T.F.; Kellum, M.E.; Porter, S.S.; Bell, M.; Schaffner, W. An outbreak of community-acquired foodborne illness caused by methicillin-resistant Staphylococcus aureus. Emerg. Infect. Dis. 2002, 8, 82-84. [CrossRef]

9. Mediavilla, J.R.; Chen, L.; Mathema, B.; Kreiswirth, B.N. Global epidemiology of community-associated methicillin resistant Staphylococcus aureus (CA-MRSA). Curr. Opin. Microbiol. 2012, 15, 588-595. [CrossRef]

10. Dhama, K.; Tiwari, R.; Chakraborty, S.; Saminathan, M.; Kumar, A.; Karthik, K.; Wani, M.Y.; Amarpal; Singh, S.V.; Rahal, A Evidence Based Antibacterial Potentials of Medicinal Plants and Herbs Countering Bacterial Pathogens Especially in the Era of Emerging Drug Resistance: An Integrated Update. Int. J. Pharmacol. 2014, 10, 1-43. [CrossRef]

11. Aires-de-Sousa, M. Methicillin-resistant Staphylococcus aureus among animals: Current overview. Clin. Microbiol. Infect. 2017, 23, 373-380. [CrossRef]

12. Jin, X.; Song, S.; Wang, J.; Zhang, Q.; Qiu, F.; Zhao, F. Tiliroside, the major component of Agrimonia pilosa Ledeb ethanol extract, inhibits MAPK/JNK/p38-mediated inflammation in lipopolysaccharide-activated RAW 264.7 macrophages. Exp. Ther. Med. 2016, 12, 499-505. [CrossRef] [PubMed]

13. Kim, C.Y.; Yu, Q.M.; Kong, H.J.; Lee, J.Y.; Yang, K.M.; Seo, J.S. Antioxidant and Anti-Inflammatory Activities of Agrimonia pilosa Ledeb. Extract. Evid. Based Complement. Alternat. Med. 2020, 2020, 8571207. [CrossRef] [PubMed]

14. Yamaki, M.; Kashihara, M.; Ishiguro, K.; Takagi, S. Antimicrobial Principles of Xian he cao (Agrimonia pilosa). Planta Med. 1989, 55, 169-170. [CrossRef]

15. Liu, Y.Q.; Wang, H.W.; Cai, X. Optimization of the extraction of total flavonoids from Scutellaria baicalensis Georgi using the response surface methodology. J. Food Sci Tech. Mys. 2015, 52, 2336-2343. [CrossRef]

16. Sarker, S.D.; Nahar, L.; Kumarasamy, Y. Microtitre plate-based antibacterial assay incorporating resazurin as an indicator of cell growth, and its application in the in vitro antibacterial screening of phytochemicals. Methods 2007, 42, 321-324. [CrossRef]

17. Ma, Y.; Wang, Y.; Zhang, H.; Sun, W.; Li, Z.; Zhang, F.; Zhang, H.; Chen, F.; Zhang, H.; An, J.; et al. Antimicrobial mechanism of strictinin isomers extracted from the root of Rosa roxburghii Tratt (Ci Li Gen). J. Ethnopharmacol. 2020, 250, 112498. [CrossRef]

18. Esmadi, F.T.; Khabour, O.F.; Abbas, K.; Mohammad, A.E.; Obeidat, R.T.; Mfady, D. Synthesis, characterization and biological activity of some unsymmetrical Schiff base transition metal complexes. Drug Chem. Toxicol. 2016, 39, 41-47. [CrossRef]

19. Dhawan, A.; Bajpayee, M.; Parmar, D. Comet assay: A reliable tool for the assessment of DNA damage in different models. Cell Biol. Toxicol. 2009, 25, 5-32. [CrossRef] [PubMed]

20. Clement, C.C.; Aphkhazava, D.; Nieves, E.; Callaway, M.; Olszewski, W.; Rotzschke, O.; Santambrogio, L. Protein expression profiles of human lymph and plasma mapped by 2D-DIGE and 1D SDS-PAGE coupled with nanoLC-ESI-MS/MS bottom-up proteomics. J. Proteom. 2013, 78, 172-187. [CrossRef]

21. Grigor'eva, A.; Bardasheva, A.; Tupitsyna, A.; Amirkhanov, N.; Tikunova, N.; Pyshnyi, D.; Ryabchikova, E. Changes in the Ultrastructure of Staphylococcus aureus Treated with Cationic Peptides and Chlorhexidine. Microorganisms 2020, 8, 1991. [CrossRef]

22. Zhu, L.; Chen, J.; Tan, J.; Liu, X.; Wang, B. Flavonoids from Agrimonia pilosa Ledeb: Free Radical Scavenging and DNA Oxidative Damage Protection Activities and Analysis of Bioactivity-Structure Relationship Based on Molecular and Electronic Structures. Molecules 2017, 22, 195. [CrossRef] [PubMed]

23. Pan, Y.; Liu, H.X.; Zhuang, Y.L.; Ding, L.Q.; Chen, L.X.; Qiu, F. Studies on isolation and identification of flavonoids in herbs of Agrimonia pilosa. Zhongguo Zhong Yao Za Zhi 2008, 33, 2925-2928. [PubMed]

24. Donnapee, S.; Li, J.; Yang, X.; Ge, A.H.; Donkor, P.O.; Gao, X.M.; Chang, Y.X. Cuscuta chinensis Lam.: A systematic review on ethnopharmacology, phytochemistry and pharmacology of an important traditional herbal medicine. J. Ethnopharmacol. 2014, 157, 292-308. [CrossRef] [PubMed]

25. Liancai, Z.; Jun, T.; Bochu, W.; Rui, H.; Yuping, L.; Chao, Z. Antioxidant activities of aqueous extract from Agrimonia pilosa Ledeb and its fractions. Chem. Biodivers. 2009, 6, 1716-1726. [CrossRef]

26. Kim, S.B.; Hwang, S.H.; Suh, H.W.; Lim, S.S. Phytochemical Analysis of Agrimonia pilosa Ledeb, Its Antioxidant Activity and Aldose Reductase Inhibitory Potential. Int. J. Mol. Sci. 2017, 18, 379. [CrossRef]

27. Liu, W.J.; Hou, X.Q.; Chen, H.; Liang, J.Y.; Sun, J.B. Chemical constituents from Agrimonia pilosa Ledeb. and their chemotaxonomic significance. Nat. Prod. Res. 2016, 30, 2495-2499. [CrossRef]

28. Jiang, Q.H.; Ma, J.H.; Wang, Y.; Ding, L.Q.; Chen, L.X.; Qiu, F. Simultaneous determination of nine major constituents in Agrimonia pilosa Ledeb. by HPLC-DAD-ESI-MS/MS. Anal. Methods 2014, 6, 4373-4379. [CrossRef] 
29. Babeshina, L.G.; Kuznetzov, A.A.; Reshetov, Y.E.; Krasnov, E.A. Agrimony pilosa Ledeb. (Rosaceae)-Chemical Composition, Biological Effects and Anatomy. Biosci. Biotechnol. Res. Asia 2014, 11, 65-68. [CrossRef]

30. Park, M.J.; Kang, Y.-H. Isolation of Isocoumarins and Flavonoids as $\alpha$-Glucosidase Inhibitors from Agrimonia pilosa L. Molecules 2020, 25, 2572. [CrossRef]

31. Kateete, D.P.; Bwanga, F.; Seni, J.; Mayanja, R.; Kigozi, E.; Mujuni, B.; Ashaba, F.K.; Baluku, H.; Najjuka, C.F.; Kallander, K.; et al. CA-MRSA and HA-MRSA coexist in community and hospital settings in Uganda. Antimicrob. Resist. Infect. Control $2019,8,94$. [CrossRef] [PubMed]

32. Bal, A.M.; David, M.Z.; Garau, J.; Gottlieb, T.; Mazzei, T.; Scaglione, F.; Tattevin, P.; Gould, I.M. Future trends in the treatment of methicillin-resistant Staphylococcus aureus (MRSA) infection: An in-depth review of newer antibiotics active against an enduring pathogen. J. Glob. Antimicrob. Resist. 2017, 10, 295-303. [CrossRef] [PubMed]

33. Basri, D.F.; Sandra, V. Synergistic Interaction of Methanol Extract from Canarium odontophyllum Miq. Leaf in Combination with Oxacillin against Methicillin-Resistant Staphylococcus aureus (MRSA) ATCC 33591. Int J. Microbiol. 2016, 2016, 5249534. [CrossRef]

34. Al-Habib, A.; Al-Saleh, E.; Safer, A.M.; Afzal, M. Bactericidal effect of grape seed extract on methicillin-resistant Staphylococcus aureus (MRSA). J. Toxicol. Sci. 2010, 35, 357-364. [CrossRef] [PubMed]

35. Kim, G.; Gan, R.Y.; Zhang, D.; Farha, A.K.; Habimana, O.; Mavumengwana, V.; Li, H.B.; Wang, X.H.; Corke, H. Large-Scale Screening of 239 Traditional Chinese Medicinal Plant Extracts for Their Antibacterial Activities against Multidrug-Resistant Staphylococcus aureus and Cytotoxic Activities. Pathogens 2020, 9, 185. [CrossRef] [PubMed]

36. Kim, S.Y.; Park, C.; Jang, H.J.; Kim, B.O.; Bae, H.W.; Chung, I.Y.; Kim, E.S.; Cho, Y.H. Antibacterial strategies inspired by the oxidative stress and response networks. J. Microbiol. 2019, 57, 203-212. [CrossRef]

37. Horsburgh, M.J.; Clements, M.O.; Crossley, H.; Ingham, E.; Foster, S.J. PerR controls oxidative stress resistance and iron storage proteins and is required for virulence in Staphylococcus aureus. Infect. Immun. 2001, 69, 3744-3754. [CrossRef]

38. Valavanidis, A.; Vlachogianni, T.; Fiotakis, C. 8-hydroxy-2' -deoxyguanosine (8-OHdG): A critical biomarker of oxidative stress and carcinogenesis. J. Environ. Sci. Health C Environ. Carcinog. Ecotoxicol. Rev. 2009, 27, 120-139. [CrossRef]

39. Choe, M.; Park, Y.H.; Lee, C.R.; Kim, Y.R.; Seok, Y.J. The general PTS component HPr determines the preference for glucose over mannitol. Sci. Rep. 2017, 7, 43431. [CrossRef]

40. Zebre, A.C.; Ake, F.M.; Ventroux, M.; Koffi-Nevry, R.; Noirot-Gros, M.F.; Deutscher, J.; Milohanic, E. Interaction with enzyme IIBMpo (EIIBMpo) and phosphorylation by phosphorylated EIIBMpo exert antagonistic effects on the transcriptional activator ManR of Listeria monocytogenes. J. Bacteriol. 2015, 197, 1559-1572. [CrossRef]

41. Zhou, Y.; Cai, M.; Zhou, H.; Hou, L.; Peng, H.; He, H. Discovery of efficient inhibitors against pyruvate dehydrogenase complex component E1 with bactericidal activity using computer aided design. Pestic. Biochem. Physiol. 2021, 177, 104894. [CrossRef] [PubMed]

42. Patel, M.S.; Korotchkina, L.G.; Sidhu, S. Interaction of E1 and E3 components with the core proteins of the human pyruvate dehydrogenase complex. J. Mol. Catal. B Enzym. 2009, 61, 2-6. [CrossRef] [PubMed]

43. Kumar, Y.P.; Gurmit, S.; Budhayash, G.; Satendra, S.; Madhu, Y.; Upasana, S.; Brijendra, S. Molecular modeling, dynamics studies and virtual screening of Fructose 1, 6 biphosphate aldolase-II in community acquired- methicillin resistant Staphylococcus aureus (CA-MRSA). Bioinformation 2013, 9, 158-164. [CrossRef]

44. Callens, M.; Kuntz, D.A.; Opperdoes, F.R. Kinetic properties of fructose bisphosphate aldolase from Trypanosoma brucei compared to aldolase from rabbit muscle and Staphylococcus aureus. Mol. Biochem. Parasitol. 1991, 47, 1-9. [CrossRef]

45. Zengel, J.M.; Lindahl, L. Ribosomal protein L4 of Escherichia coli: In vitro analysis of L4-mediated attenuation control. Biochimie 1991, 73, 719-727. [CrossRef]

46. Locke, J.B.; Hilgers, M.; Shaw, K.J. Novel Ribosomal Mutations in Staphylococcus aureus Strains Identified through Selection with the Oxazolidinones Linezolid and Torezolid (TR-700). Antimicrob. Agents Chemother. 2009, 53, 5265-5274. [CrossRef] 